\title{
O SISTEMA DAS CIÊNCIAS E O LUGAR DA GEOGRAFIA*
}

\author{
ALFRED HETTNER
}

O sistema das ciências se baseava no passado exclusivamente nas relações ou na diversidade dos objetos, ou seja, as ciências se estruturavam de acordo com as afinidades concretas de seus objetos. Alguns sistematizadores ingênuos, sobretudo os que se originam das ciências particulares e não se tomam o encargo de considerar o sistema das ciências, prosseguem, ainda hoje, agindo assim. Os filósofos sistemáticos, porém, superaram essa concepção e reconheceram que a interpretação das coisas desde o ponto de vista das afinidades concretas é simplista, assim como admitem a possibilidade e a necessidade de outra concepção, baseada em pontos de vista completamente opostos, que permita o nascimento de ciências especiais. Tais filósofos, entretanto, pouco ainda desenvolveram essa concepção e omitiram precisamente o ponto de vista que resulta decisivo para a integração lógica da geografia. Deixaram-se levar pela definição, em princípio bastante lógica, da geografia como ciência da terra, incluindo-a sob essa concepção em seu sistema, sem ter em conta a concepção dual desta ciência, de modo que ou a geografia humana fica excluída ou a geografia fica dividida entre as diferentes partes do seu sistema de classificação.

A primeira distinção fundamental dentro das ciências experimentais teóricas, que aqui nos interessam, é a estabelecida por Comte entre as ciências abstratas e as ciências concretas. Esta distinção não significa que as primeiras tenham menos relação com os objetos concretos que as segundas, no sentido de objetos reais perceptíveis

\footnotetext{
* Fragmento de La Naturaleza de la Geografia y Sus Métodos, traduzido de El Pensamiento Geográfico, Josefina Mendoza et Alli, Alianza Editorial, Madri, 1982, por Ruy Moreira, do Departamento de Geografia da UFF.
} 
pelos sentidos, mas sim que as ciências abstratas despojam-nos de todas as suas características especiais e individuais para investigar somente os processos ou qualidades gerais, como, por exemplo, a gravidade, a luz, o magnetismo, a natureza física como tal, enquanto que, ao contrário, as ciências concretas entendem sempre os processos e condições gerais como qualidades de determinados corpos. Porém a distinção entre ciências abstratas e ciências concretas não é muito marcada. Podemos dizer que existe uma transição desde as ciências completamente abstratas, como a física, a química e a psicologia, passando pelas ciências que têm alguma relação com a natureza ou a mente, como a mineralogia, a botânica, a fisiologia, a sociologia e a economia política geral, até às ciências concretas voltadas para os conceitos individuais e coletivos. Esta diferenciação coincide até certo ponto com a diferenciação recentemente estabelecida entre ciências nomotéticas e ciências ideográficas, ou entre ciências de leis e ciências de eventos, de forma pouco afortunada designadas por ciência natural e ciência cultural ou histórica. Esta diferenciação produz a falsa impressão de que o fim das primeiras é o estabelecimento de conceitos gerais e legais ao passo que o das segundas é o conhecimento do singular. Os conceitos e leis gerais constituem a finalidade do conhecimento das ciências abstratas, mas na medida da aproximação analítica da síntese que perseguem, seja a síntese reprodutiva da ciência, seja a síntese produtiva da técnica e da prática. As ciências abstratas não cobrem o conhecimento completo da realidade, apenas o preparam e fundamentam. O conhecimento da realidade em si encontra-se dividido entre as diversas ciências concretas.

As ciências concretas se referem à realidade de acordo com a versatilidade do conteúdo das coisas e as diferenças de seu comportamento no espaço e no tempo. Podem partir, portanto, de três pontos de vista diferentes e, desse modo, configuram três agrupamentos principais.

Uma parte importante, talvez a maioria, das ciências concretas, que em seu conjunto poderiam denominar-se ciências sistemáticas, põe umas depois das outras as condições temporais e espaciais, e encontra sua unidade na homogeneidade ou na afinidade dos objetos dos quais se ocupa. A distinção habitual das ciências entre ciências da natureza e ciências do espírito se baseia em uma diferenciação sistemática desse tipo. Dentro das ciências naturais desenvolveram-se em primeiro lugar as ciências dos minerais e das rochas (mineralogia e petrologia), das plantas (botânica), dos animais (zoologia), junto às quais criou-se por diversos motivos a ciência das plantas e animais fósseis (paleontologia). Mais tarde incorporou-se também o estudo do corpo terrestre e de seus fenômenos, cujo lugar científico está definido na descrição da geografia geral. As ciências das línguas podem ser consideradas ciências sistemáticas do espírito, assim como a ciência da religião, a ciência política, a ciência econômica e outras. Porém, junto com os princípios sistemáticos da distribuição interfere um outro princípio de distribuição que define a transição aos dois outros grupos principais das ciências concretas, o princípio que se rege pelas diferenças das áreas linguísticas e culturais, dando lugar à filologia e à etnologia. 
A afinidade do conteúdo dos objetos é secundária para as ciências históricas. Estas reúnem em seu estudo uma série de objetos pertencentes a distintos sistemas e que retiram sua homogeneidade desse ponto de vista tão especial que é a consideração do desenvolvimento temporal das coisas. Se estas coisas se sucedessem casualmente no tempo e se a evolução dos distintos grupos de fenômenos fosse independente, a ciência poderia declarar-se satisfeita com a aproximação sistemática. Porém a conexão das distintas épocas que expressamos com a palavra desenvolvimento e a conexão das diferentes coisas em uma mesma época, obrigam a uma consideração histórica específica. $\mathrm{O}$ estudo do desenvolvimento histórico de um único grupo de fenômenos, correspondendo assim unicamente a um dos dois pontos de vista indicados, como, por exemplo, a história da fauna ou da arte, ou da história das constituições, situa-se em uma posição intermediária entre as ciências sistemáticas e as ciências históricas. As ciências verdadeiramente históricas abrangem todos os fenômenos, porém se dividem em três ciências distintas. A primeira é a ciência da história da terra ou geologia histórica, que não é unicamente a história da crosta terrestre, mas também a história do clima e do mundo das plantas e dos animais. A segunda é a pré-história, que foi durante muito tempo uma ciência sistemática, mostrando agora um caráter autenticamente histórico devido à periodização de suas descobertas. A terceira é a história propriamente dita, isto é, a história cultural do homem, que ultimamente começou a superar tanto a limitação à área cultural da Ásia Menor e da Europa como a limitação do tratamento das condições dos Estados, ainda que siga lutando para conseguir um método verdadeiramente histórico universalmente aplicável.

Em situação semelhante ao desenvolvimento no tempo, o ordenamento das coisas no espaço tem direito a uma consideração especial. E é significativo observar que os especialistas em lógica que reconheceram a necessidade do primeiro não tenham se dado conta do segundo. A realidade é um espaço tridimensional que observamos desde três pontos de vista. Em primeiro lugar, vemos as conexões de uma interrelação material; em segundo, vemos o desenvolvimento no tempo; e em terceiro, a distribuição e a ordem no espaço. Na medida em que renunciamos à utilização da terceira perspectiva, a realidade se torna bidimensional. Não a vemos em toda a sua extensão e variedade. Daí se deduz que devem aparecer ciências corológicas junto às ciências sistemáticas e cronológicas.

Existem duas ciências corológicas.

Uma delas se ocupa do ordenamento das coisas no espaço universal: é a astronomia, que no passado se entendeu indevidamente como uma mecânica aplicada, isto é, como uma ciência de leis abstratas, quando seu verdadeiro objeto é a constelação e a natureza dos distintos astros. A outra ciência corológica é a ciência do ordenamento do espaço terrestre, ou, posto que não conhecemos o interior da terra, da superfície terrestre. Uma ciência corológica deste tipo é necessária por razões muito parecidas às que justificam a ciência cronológica da história. Se não houvesse relações entre os distintos pontos da superfície terrestre e se os diferentes fenômenos situados em um mesmo lugar fossem independentes entre si, não seria necessária nenhuma concepção 
corológica. Porém a existência destas relações, que as ciências sistemáticas e históricas aludem ou apenas podem tratar, torna necessária uma ciência corológica especial da terra. Essa ciência é a geografia.

A consideração do desenvolvimento histórico da geografia como ciência nos mostra que em todo momento fez-se referência ao conhecimento dos distintos espaços da terra, e que ao longo do tempo só mudou o método de estudo, devido ao progresso dos resultados científicos. Os metodólogos que não perderam o contato com o desenvolvimento científico sempre situaram por isso no lugar preferido o ponto de vista do ordenamento do espaço. A geografia de Ritter encontra-se indubitavelmente dominada por esta concepção, à qual se refere quando denomina a geografia como ciência dos espaços e quando trata de sua função. Após a confusão metodológica introduzida na geografia por Peschel, ao tempo que propiciou revolucionária transformação à geografia física, F. von Richthofen voltou a ressaltar o verdadeiro ponto de vista da geografia, denominando-a ciência da superfície terrestre, referindo-se à superfície sólida. Imediatamente depois de Richthofen, Marthe ampliou esse conceito e ressaltou com força o ponto de vista corológico, ainda que em um sentido equivocado, denominando a geografia de ciência do onde das coisas. Nas conferências posteriores de Richthofen, em Leipzig, apresenta-se uma concepção de geografia que configura o programa da geografia atual, ajustando o conceito de Marthe e aceitando por sua vez as posições de Ritter, já que o conceito de superfície terrestre perdeu seu sentido restrito e inclui a crosta terrestre sólida, a água, a atmosfera, a flora, a fauna e o homem.

Numerosos metodólogos modernos adotaram as linhas gerais dessa perspectiva e a aproximação corológica ocupa uma posição preferida inclusive no caso daqueles geógrafos que, em teoria, partem do conceito de geografia como ciência da terra e rendem culto à opinião "dualista". Entre estes geógrafos se encontram A. Kirchhoff e H. Wagner.

Resumindo os resultados de nossas considerações, podemos afirmar que não se deve renunciar à concepção, historicamente válida, da geografia como ciência corológica da superfície terrestre, ou ciência dos espaços terrestres, que se organiza com base em suas diferenças e nas relações entre os seus diferentes pontos, não só porque a lógica sistemática de outras concepções não resulta nem historicamente comprovada e nem praticamente realizável, mas porque, pelo contrário, constitui a exigência de uma sistemática das ciências logicamente completa. 